\section{Denise Duarte}

Joana Carla S. Gonçalves

Roberta C. Kronka Mülfarth

\section{DeSeMPENHO De eDIFÍCIOS, eNSINO De TeCNOLOGIA DA ARQ $u$ IT $e$ T $U$ RA, CeRTIFICAÇÃO AMBIeNTAL De eDIFÍCIOS}

\author{
UALFRIDO DEL CARLO
}

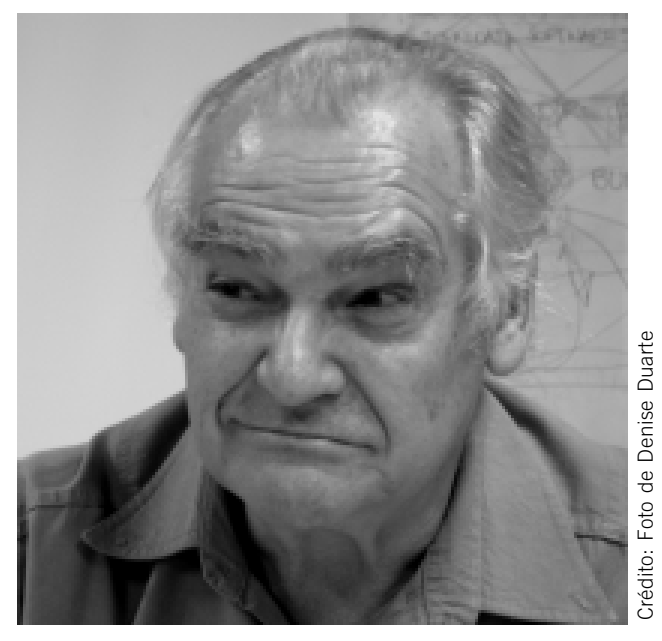

Entrevista com o Prof. Dr. Ualfrido Del Carlo, professor titular aposentado na Universidade de São Paulo, vinculado à Faculdade de Arquitetura e Urbanismo desde 1964, chefe do Departamento de Tecnologia da FAUUSP, de 1980 a 1982 e também de 1984 a 1986, diretor da FAUUSP de 1986 a 1990, pesquisador e chefe da seção de Tecnologia Microambiental do Instituto de Pesquisas Tecnológicas do Estado de São Paulo - IPT, de 1972 a 1982, e chefe do Agrupamento de Tecnologia Ambiental - ATA, por dois anos, no final da década de 1970.

Este depoimento foi gravado em 01 de outubro de 2007, no Laboratório de Conforto Ambiental e Eficiência Energética do Departamento de Tecnologia. O depoimento foi conduzido pela professoras doutoras Denise Duarte, Joana Carla Soares Gonçalves e Roberta Consentino Kronka Mülfarth, do grupo de disciplinas de Conforto Ambiental e Eficiência Energética do mesmo departamento. 
(1) CSTB - Centre Scientifique et Technique du Batiment, França.

(2) CSTC-Centre Scientifique et Technique de la Construction, Bélgica.

(3) Centro de Tecnologías Físicas Leonardo Torres Quevedo, Espanha.

(4) BRE - Building Research Establishment, Inglaterra.

(5) LNEC - Laboratório Nacional de Engenharia Civil, Portugal.

(6) DIN - Deutsches Institut für Normung e. V., Alemanha.

(7) BLACHĖRE, Gérard. Savoir bâtir: Habitabilité, durabilité, économie des batiments. Paris: Eyrolles, 1965.

\section{Apresentação}

Neste depoimento, Ualfrido Del Carlo fala sobre o conceito de desempenho do ambiente construído, sobre sua passagem pelo Centre Scientifique et Technique du Batiment - CSTB, no final da década de 1960, início de 1970, sobre como o assunto foi abordado pelo Departamento de Tecnologia da FAUUSP, desde sua criação, em 1964, e por outras instituições de ensino e pesquisa em diferentes lugares do mundo, bem como a proposta de uma nova estrutura para o ensino de tecnologia nas escolas de arquitetura. Outro tema tratado são as novas variáveis que hoje fazem parte do trabalho de arquitetos e urbanistas: sustentabilidade, meio ambiente e responsabilidade social, e a certificação ambiental de edifícios.

Revista Pós: Como e quando surgiu o conceito de desempenho do ambiente construído? Qual é o histórico, resumidamente?

Ualfrido Del Carlo: Depois da Segunda Guerra Mundial, a Europa estava destruída em grande parte e precisava iniciar sua reconstrução. Esse recomeço foi baseado na tradição da construção, e os edifícios foram reconstruídos da mesma forma como eram feitos antes da guerra. Só que deu zebra. No pós-guerra as exigências mudaram, novas tecnologias foram desenvolvidas durante a guerra, as exigências de conforto, de desempenho de materiais eram outras, e o descontentamento com a qualidade dos ambientes construídos foi geral nos anos 50 e 60 . Nos anos 70 os edifícios do pós-guerra começaram a ser derrubados e reconstruídos.

Ao mesmo tempo, os principais laboratórios foram montados depois da guerra: CSTB ${ }^{1}, \mathrm{CSTC}^{2}$, Torres Quevedo ${ }^{3}, \mathrm{BRE}^{4}, \mathrm{LNEC}^{5}$, assim como as principais normatizações, como a DIN ${ }^{6}$. Alguns já existiam antes, mas passaram a funcionar mesmo depois da guerra.

Gérard Blachère, diretor-presidente do CSTB na época, fez uma proposta de desempenho na década de 1960. Ele escreveu o Savoir bâtir (Saber construir) ${ }^{7}$, que é uma bíblia, "pra" começar, e foi montado um laboratório baseado nisso, com auxílio de muitos técnicos. Era um laboratório para verificar tudo, desempenho global mesmo. Eu presenciei o processo, quando eles estavam implantando esse sistema.

$\mathrm{Na}$ época eram comuns conjuntos de umas 1.000 unidades de apartamentos, com muitas torres, etc. O projeto vinha, passava pelos 14 itens, um em cada laboratório, e depois voltava para o tal escritório de desempenho, em paralelo; voltava para se avaliar o desempenho global. Uma dessas unidades era escolhida e um técnico do CSTB ia morar lá por um ano "pra" fazer o monitoramento. A unidade era instrumentada, e o técnico era remunerado para medir tudo: térmica, iluminação, acústica - era um laboratório montado dentro de uma residência. 
OI 2

(8) ISO 9000 - Quality management systems.

(9) ISO 6241 -

Performance standards in building - Principles for their preparation and factors to be considered.
E esse processo funcionava como realimentação do sistema como um todo, para todo o país. Não era só uma APO - Avaliação Pós-Ocupação, mas tinha a APO junto. Na época, a APO na França, ao contrário da nossa e dos americanos, tinha umas 200 perguntas; eles perguntavam tudo, e o usuário era remunerado para responder; um manual ia junto, para orientar as respostas, e os técnicos faziam a realimentação de tudo, uma realimentação de todos os $h, I, m-$ habitacion, location e moyenne. Tudo o que passava de 10 anos para pagar era locação, não era venda. Na época os moradores tinham 10 anos para pagar, como um leasing. Com mais de 20 prestações, o contrato era como um leasing. Olha como era inteligente. Mas isso acabou. Hoje não se faz mais conjuntos grandes, porque isso criou problemas, por questões de guetos, de problemas sociais. Os conjuntos iam se deteriorando, iam se formando guetos e, ao final, só ficavam os mais pobres. Isso só melhorou depois de uma mudança de um governo de direita para um governo socialista democrático.

$\mathrm{O}$ que eles fizeram? Hoje, quando se constroem 50 casas, por exemplo, precisa-se ter, no mínimo, três segmentos sociais. Esses três segmentos (diferentes dos nossos) são nível médio, nível A e os mais ricos; os filhos teriam de estudar na mesma escola, juntos. Então esses novos empreendimentos são sempre pequenos. Não tem mais aquela coisa de 1.000 unidades.

Vamos em frente. E assim foi acontecendo a evolução do "desempenhinho tecnológico" (faltava o social) para o que chamo de "desempenhão" (que inclui o social).

Mais de uma década depois, no meio científico e tecnológico da construção, nasce o conceito de qualidade, com o surgimento da família de normas ISO $9000^{8}$, nos anos 80 - é o que o consumidor quer, e não só a parte técnica.

No Brasil, ninguém atende à ISO $6241^{9}$, mas a ISO 9000 pegou, só que ela garante coisas boas e ruins com a mesma qualidade. Só o controle de qualidade não garante nada! $\mathrm{O}$ controle de qualidade garante que todos vão sair com a mesma qualidade, independente de um desempenho satisfatório ou não. Todos os carros saem com o mesmo defeito na porta, por exemplo! Isso é controle de qualidade sem desempenho.

De qualquer forma, faltam todos os ensaios de desempenho, tudo tem de ser testado. Lá fora é o seguinte, não tem conversa: ou usa o convencional do qual se conhece o resultado porque já está tudo em uma tabela, ou ensaia tudo, tem de testar. Testou, precisa divulgar, e saem publicados todos os resultados que foram feitos. Não se joga no mercado nada que não foi testado. Todo produto tem de ter o desempenho garantido.

RP: Por que a ISO 6241 não pegou no Brasil?

UDC: Normas têm interesse político por trás, política dos materiais, política da construção; cada sociedade assume as normas que Ihe convém, e nossa sociedade enxergou a ISO 6241 como um sistema que não serve à construção civil, porque ela envolve custos altos na fase de testes, é verdade, mas que vão ser muito mais altos depois que os problemas aparecerem. É muito mais barato testar antes do que corrigir depois: são vazamentos de tubulações, problemas acústicos, forros que descolam, sistemas de ar-condicionado com muito barulho, coisas desse tipo que não foram testadas e depois dá zebra. Mas eles não entenderam que é uma necessidade, não temos até hoje um laboratório de 
desempenho completo. Quando digo eles, isso inclui governo, mercado, consumidor, todos. Nesse ponto o Brasil é o país do mais ou menos.

Veja um exemplo: Qual é a isolação acústica do apartamento que você comprou? Você tem os dados de desempenho? Quantos decibéis? A construtora é que deveria te informar. O seu apartamento é bem orientado? Porque se tem quatro apartamentos por andar e as fachadas são iguais, três deles não são; o que fica virado para o barulho deveria ter janelas acústicas, por exemplo. Olha que horror! Como pode haver quatro apartamentos com orientações diferentes e envoltórias todas iguais? Com certeza tem uns piores do que os outros.

RP: Como você interpreta o desempenho como ferramenta para o processo de projeto?

UDC: O conceito de desempenho nasceu para abrir o sistema. Você pode usar materiais novos, não interessa como é feito, mas precisa atender aos 14 itens de desempenho. Vai para os laboratórios, testa tudo, e aí pronto. Isso para atender à liberdade de criação e a um mercado mais livre e aberto para materiais novos.

Estabilidade é o primeiro requisito de desempenho de todos, tem de ficar em pé, não importa como. Posso fazer um prédio inflável, que vai ficar a $10 \mathrm{~m}$ do solo, mas ancorado, com paredes infláveis, com isolação térmica espetacular, etc. É proibido? Não deveria. Em um caso como esse atendo ao requisito de fundações com a ancoragem, ele só não pode voar: se for estanque, seguro ao uso, ao fogo, etc, etc, então pronto. O desempenho foi atendido. Dessa forma, nada seria proibido, desde que atendesse aos requisitos de desempenho. Você vai para o laboratório e testa tudo; isso nos levaria a um mercado mais livre e aberto para materiais novos, para a criatividade, mas o país não funciona assim.

RP: Como o mercado e a indústria da construção, no Brasil, tratam a questão do desempenho?

UDC: De maneira geral, o sistema brasileiro é baseado na escravidão, ainda construímos edifícios em vários setores, assentando um tijolo sobre o outro, ainda têm trabalhadores que ganham $R \$ 400,500,600 /$ mês para isso. Se ainda tem quem pode ganhar isso, faço uma baita estrutura, e vou assentando um tijolinho sobre o outro, um bloco sobre o outro.

Hoje vivemos no que chamo de um sistema híbrido no mercado da construção, no qual alguns edifícios são totalmente industrializados, usam aço escovado, painéis espetaculares, poliuretano, com o diabo de materiais novos e, por outro lado, há outros que vejo quando desço do ônibus, quando vou "pra" minha casa, e me "dão nos nervos"; são edifícios de 20 e poucos andares, com uma estrutura perfeita, linda, bem feitinha, mas construídos tijolinho por tijolinho, um em cima do outro. Sistemas construtivos industrializados permitiriam pagar muito bem aos trabalhadores, porque poderiam ser produzidos em quantidades muito grandes. Mas continuam pagando uma porcaria, e o dinheiro vai para o cara que constrói.

Agora há um boom na construção de edifícios residenciais, com a economia mais estável, com mais financiamentos, mas não vejo isso se refletir na tecnologia construtiva, na industrialização, na facilidade de manutenção; enquanto isso, continua vigente, nesse setor, a parede de alvenaria. Estamos em um sistema híbrido, não conseguimos começar a entender como um sistema aberto.

RP: Como o Departamento de Tecnologia da FAUUSP tratou e trata a questão do desempenho? 


\section{OI4}

(10) ISO 6241 -

International Organization for Standardization. Performance standards in buildings: Principles for their preparation and factors to be considered. Londres, 1984. São 14 itens de desempenho: 1 . Segurança estrutural; 2. Segurança ao fogo; 3 . Segurança ao uso; 4. Estanqueidade; 5. Higiene; 6. Qualidade do ar; 7. Conforto higrotérmico; 8. Conforto visual; 9. Conforto acústico; 10. Conforto tátil; 11. Conforto antropodinâmico; 12 . Conforto antropométrico; 13. Durabilidade; 14. Economia (tradução livre).

(11) Arquiteto Carlos Alberto de Abreu Maffei.
UDC: $\mathrm{O}$ departamento trata boa parte da questão de desempenho, mas ainda não assumiu o desempenho como a linha mestra de atuação e de estruturação das disciplinas e das pesquisas: acústica, higrotermia e iluminação são tratadas desde a criação do departamento, em 1964, mas ainda faltam algumas coisas. São 14 itens ao todo ${ }^{10}$.

Até hoje não temos disciplinas obrigatórias de segurança contra incêndio, economia e durabilidade de materiais, durabilidade da construção, adequação dos espaços ao uso, segurança ao uso, o que poderia envolver a FAU inteira (e não é só ergonomia) e estanqueidade, por exemplo. Tudo vaza neste país, e, pelo conceito de desempenho, você pode impermeabilizar como quiser, não importa como, o importante é não vazar. Essa é a visão do desempenho. Em paralelo, precisa ensinar como se faz, em disciplinas de solos, fundações, estruturas, vedos, instalações e equipamentos.

O ideal é estruturar uma matriz de desempenho versus todos os itens, com as interações entre eles, por exemplo: solos/fundações; vedos/segurança ao uso, etc. Há interação de solos com acústica? Há problema de solos com estrutura? Claro que há.

RP: Pensando no ensino, como vamos incentivar nossos alunos a criarem com essa concepção de desempenho?

UDC: Deveríamos ocupar não mais do que $10 \%$ do ensino de tecnologia com o ensino de técnicas tradicionais, convencionais. Isso não pode se perder, não podemos deixar, mas assentar tijolo a gente aprende na internet, é só passar a bibliografia para eles estudarem sozinhos. Não precisa ensinar na aula. 0 restante do curso é para inovação.

RP: Como foi a experiência do IPT na questão do desempenho?

UDC: A experiência do IPT com a questão do desempenho não foi muito diferente da FAU: são iguais, só implantamos uma parte, nunca implantamos um laboratório de desempenho, de fato, no IPT; só existe um no Brasil, funcionando mais ou menos em Goiânia. O laboratório de Furnas - Laboratório de Desenvolvimento de Sistemas Construtivos - foi feito para isso, por desempenho mesmo, e até hoje funciona aquém de sua capacidade.

No IPT eu tinha o laboratório de tecnologia microambiental: iluminação, acústica, térmica e fogo. Não fiquei com o desempenho todo, que era do Maffei ${ }^{11}$, arquiteto formado pelo Mackenzie, já falecido, que tinha feito mestrado na Inglaterra, enquanto eu fiquei como chefe do agrupamento como um todo, mas nunca consegui colocar tudo lá como a gente precisava.

Existe uma exigência de desempenho mecânico dos materiais, que é muito importante para se saber se uma parede agüenta duas pessoas brigando, por exemplo. Nesse ensaio, transmite-se à parede certa quantidade de energia para se avaliar o quanto ela agüenta. É uma máquina de impacto; simplificando, é uma bolinha de aço que a gente vai batendo "pra" ver se deforma a parede.

Mas no IPT isso nunca se transformou no que chamo de aval total de desempenho da edificação, para englobar todas as partes e estudar o todo. É um check list, que pega um edifício e vê se ele atende aos 14 itens.

Mas isso tudo o que falamos até agora é da década de 1980 do século passado, ou melhor, do milênio passado; então, nesse intervalo, surgiram novas variáveis, e é disso que quero falar agora. 
(12) Instituto Tecnológico da Aeronáutica, em São José dos Campos-SP.

(13) Prof. Dr. João Gualberto de Azevedo Baring, do Grupo de Disciplinas de Conforto Ambiental do Departamento de Tecnologia da FAUUSP.
RP: Antes disso, como se deu sua ida para o CSTB?

UDC: Eu me afastei temporariamente da FAU para a Europa, trabalhei no CSTB no período 1969/1971, por quase dois anos letivos, com bolsa da Fapesp. Fui encaminhado pelo professor Luiz Cintra do Prado, meu orientador na época. Fui lá para aprender, porque não tinha mais como prosseguir aqui.

No retorno, voltei para a FAU e só depois saí novamente, emprestado para o IPT, depois de 10 anos de casa.

Na época, meu chefe, o meu outro guru, o professor Paulus Aulus Pompéia, que tinha saído da FAU para a vaga do professor Luiz Cintra do Prado - e o Pompéia era um homem muito correto, um dos homens mais corretos que eu encontrei na minha vida - trouxe o professor Cintra do Prado de volta para a FAU, e o Departamento de Tecnologia tinha em seus quadros, nessa ocasião, nada menos do que o presidente da Comissão Nacional de Energia Atômica e o ex-reitor do ITA ${ }^{12}$; era assim nosso Departamento de Tecnologia na época, fora os outros, muito bons também, para dar aula de Física de Construções, que era como se chamava o Conforto Ambiental na época.

Depois o Paulus Pompéia saiu e foi para o IPT, como assessor da superintendência. Eles estavam montando as coisas lá e chamaram-me para o IPT. O Maffei foi à minha casa me procurar e perguntou se eu queria trabalhar no IPT, emprestado pela FAU, e eu aceitei. Nesse período fiquei em tempo parcial na FAU por causa disso, e fazia 12 horas semanais aqui, eu vinha para dar aulas aqui, e 1.000 horas por semana no IPT, dia e noite; fiquei assim por 10 anos, emprestado pela FAU. Como tinha ido daqui "pra" lá, muitas vezes tentaram fazer com que eu deixasse a FAU, dizendo estar atrapalhando meu trabalho lá, e eu disse que não estava atrapalhando nada, eles não tinham nada a ver com isso, eu sou de lá, e eu nunca deixei a FAU. Eu sempre disse: eu sou de lá, e vão ter de me engolir desse jeito. E vai continuar assim. Eu tinha uma carta do superintendente dizendo que eu era emprestado lá e continuava com as minhas atividades na FAU.

Para vocês terem idéia de quem era a fera, Paulus Aulus Pompéia, uma pessoa incrível, ex-reitor do ITA, brigou com os militares durante a revolução e veio para a FAU. Ficou por aqui quatro, cinco, seis anos, e montou os cadernos todos de instruções programadas que estão aí na biblioteca, de acústica, térmica e iluminação - historicamente são muito importantes, usamos por muito tempo na FAU. O Baring ${ }^{13}$ fez parte desse processo na época, ele era estagiário, e desenhou um dos cadernos de acústica.

RP: Nesse período em que você foi para o IPT houve algum convênio FAU/IPT de colaboração para pesquisas?

UDC: A primeira coisa que fiz: já que a FAU não tinha como usar os equipamentos de acústica, eles foram emprestados para o IPT, com a condição que o IPT os mantivesse funcionando, e eles viessem "pra" cá sempre que a gente precisasse. E foi muito bom porque lá eu tinha meios de manter. Eles vinham para as aulas, para demonstrações, para uso da pós-graduação, para as pesquisas. Havia alguns equipamentos muito interessantes de iluminação natural, com células fotoelétricas para medições de iluminação em diversos pontos. O problema é que alguns equipamentos, como os de acústica, voltaram "pra" cá depois de obsoletos.

RP: Como você vê o papel dos laboratórios hoje?

UDC: Nada mais é como antigamente. Além de toda a questão de padrões, tem outra questão fundamental: a grande vantagem é que os laboratórios, hoje, 
(14) Escola Politécnica da Universidade de São Paulo. permitem a realização de medidas para auxiliar nos processos de avaliação de condições espaciais (internas e externas) existentes em muitos pontos, simultaneamente, tudo com o auxílio do computador; não existe mais equipamento de medida manual e analógico. Pode usar, mas é uma frescura histórica.

Gosto muito de coisa analógica para entender o fenômeno, mas são medidas pontuais, que valem só para um ponto, com milhares de problemas. Nós sabemos que a simples presença de um equipamento de medição muda o comportamento do usuário quando ele percebe o equipamento, o que não é o objetivo da medição. O negócio é deixar um instrumento pequeno, pendurado em um poste, e deixar medindo, com datalloggers portáteis, muito pequenos. Mudou tudo hoje, posso medir e receber a distância. Posso fazer milhares de testes, de acústica, térmica e iluminação, tendo os datalloggers, um microcomputador e uma conexão via cabo ou wireless lá e aqui, e assim tenho tudo. Interfiro muito pouco no comportamento do usuário. Precisamos nos preparar para esta nova realidade.

E ainda tem a questão dos softwares. Ainda não cheguei aonde quero. Vocês já estão inventando, mais ainda está faltando. E estamos falando de edifícios, mas tem toda a tecnologia da escala urbana "pra" pensar em paralelo.

Existe, hoje, uma lei na Europa que diz: toda cidade com mais de 250.000 habitantes precisa ter um mapa de ruído. Isso é Comunidade Européia, desde o ano passado. Há um programa francês espetacular que mostra Paris com as informações de ruído à noite e de dia, em função do trânsito, do número de veículos, e você faz walkthrough. Esse negócio é muito interessante, está na internet, eu vou mostrar na próxima semana, na aula que estou dando lá na prefeitura.

O mapa de ruído é "pra" quê? Para você saber qual ruído você vai ter, se for comprar um terreno ali, quanto vai custar para tratar, qual deve ser o desempenho. Pego o mapa da cidade, tudo em 3D, daí eu já vejo tudo. Se eu for morar ali, vou precisar de uma isolação acústica de 40 dB, vou precisar fazer ventilação forçada com tratamento "pra" não entrar o barulho. À noite a coisa muda, é mais sossegado. É um problema de decisão de projeto, "pra" gente não fazer bobagem! Se eu for fazer uma habitação popular aqui, preciso saber disso, para os caras não terem problema de saúde. Isso é norma da União Européia.

RP: Aproveitando que você tocou na questão do conforto, dos anos 80 para cá, você vem formando mestres e doutores, professores, consultores, especificamente na área de conforto ambiental. Como o conforto retomou sua importância na arquitetura nos últimos anos? Quais as principais mudanças?

UDC: A primeira visão do ensino de conforto na USP foi a do professor Cintra do Prado. Para vocês entenderem, ele era engenheiro eletricista, professor de física na POLI'14 , catedrático, depois se tornou titular, tem mais de 500 artigos publicados na área de física. Ele era pianista, virtuose de piano, fazia concertos internacionais, falava vários idiomas. Ele começou e montou a questão da acústica, do conforto térmico e da iluminação na FAU. O piano era muito importante nessa história, pois ele tinha a questão da acústica muito apurada também. Era o meu guru; ele me mandou para o CSTB, era amigo do Gérard Blachère.

Passaram por aqui muitos professores da POLI, muito bons na área de acústica, térmica e iluminação. Mas ele pegou um orientando, na verdade, um 
(15) Empresa de engenharia com sede em São Paulo, fundada em 1958.

(16) Prof. Dr. Jorge Hajime Oseki, do Grupo de Disciplinas de Metodologia, do Departamento de Tecnologia da FAUUSP.

(17) Robert Josse, autor do livro Acústica en la construcción. Barcelona: Gustavo Gilli, 1975.

(18) Jean Claude Borel, autor de Confort thermique en climat chaud. São Paulo: FAUUSP, 1967, e Confort d'ete dans les constructions scolaires a structure legere. Paris: CSTB, 1969.

(19) Ambiental SC Ltda., empresa de consultoria do ex-professor da FAUUSP Luiz Carlos Chichierchio.

(20) Professor Nelson Solano, ex-professor da FAUUSP e atualmente professor da Escola da Cidade, em São Paulo. auxiliar; na época era diferente, e esse camarada era o Léo Quanji Nishikawa, já falecido. Ele era arquiteto, professor da FAU, e foi um cara muito importante, porque o Cintra dava as dicas e ele fez as apostilas com o Cintra, ele é co-autor das apostilas de iluminação natural e de acústica. A de térmica ia ser feita, mas não deu tempo. O Leo deu muita ajuda para ele fazer essas apostilas. Nunca viraram livro. O Cintra ia dando as lições para o Leo, e ele ia escrevendo. O Leo foi para a França antes de mim, é bom saber disso, uns quatro anos antes, e pegou lá o desempenho a todo vapor, depois eu peguei também.

Depois o Leo voltou, foi para a Hidroservice ${ }^{15}$ e implantou o conceito de desempenho lá. Nessa época estava lá também o Jorge Oseki ${ }^{16}$, que já tinha uma boa visão do conceito de desempenho desde aí.

Não posso esquecer de falar também que, depois de mim, foi para a França o professor Luiz Carlos Chichierchio. Teve também um outro professor do Paraná foi "pra" França antes de todo mundo, ou entre o Luiz e eu, não tenho certeza. Ele estudava acústica. Ele dava aula lá na Federal do Paraná e vinha toda semana assisitir às aulas na USP. Ele veio "pra" fazer o curso, era um rolo maluco, porque tivemos aula de térmica e de acústica com o pessoal do CSTB aqui no Brasil; vieram o Robert Josse ${ }^{17}$, meu orientador na França, e o Jean Claude Borel ${ }^{18}$, professor de térmica - há uma apostila de térmica dele na biblioteca. Eles deram aula aqui, antes da criação do curso de pós-graduação, e formaram um monte de gente, alguns professores da FAU fizeram junto, e cumpriram créditos nisso para fazer o doutorado.

Nessa época não tinha curso de pós, não tinha nada. Tudo foi inventado pelo Cintra, que trouxe esses dois caras com o Leo. O Cintra tem um valor histórico, para nós, muito grande.

RP: Quem financiou isso?

UDC: A vinda deles foi financiada certamente pelo governo francês. Tinha um programa de cooperação Brasil-França que era um monstro, vocês não têm idéia do que era possível fazer.

RP: Como foi a repercussão de tudo isso aqui no Brasil depois que esse grupo voltou do CSTB?

UDC: É muito importante entender que desse pessoal, o Chichierchio deu um impulso violento na térmica aqui, ele fez um curso específico de desempenho térmico no CSTB e abriu uma empresa, a Ambiental ${ }^{19}$, que tem um papel importante aqui nas consultorias, de conforto térmico e acústica. Ele é o cara que implementou violentamente a térmica na arquitetura aqui, deu muitos cursos no Nordeste também.

Fiz algumas besteiras, porque eu era meio linha dura, e isso criou alguns pepinos. Eu fui dar um curso de acústica no Nordeste, os caras não sabiam nem o que era $\mathrm{dB}$, não sabiam nada, falei que não dava "pra" dar aula e daí mandei o Nelson ${ }^{20}$ no meu lugar, eles queriam me matar, nunca mais me chamaram, eles acharam uma traição. Mas eles adoraram o Nelson lá, ele é bom "pra burro" e estava se formando, conhecia todas as dificuldades do aluno, e eu não conhecia nenhuma dificuldade. "Pra" mim, se não sabia logaritimo, não dava "pra" aprender acústica. Ponto!

Eu sempre falo o seguinte: como é que um cara pode fazer Conforto sem saber o que é $\Delta \mathrm{i} / \mathrm{i}$ ? Não faz. A intensidade de qualquer sensação humana é proporcional à intensidade global. A variação da intensidade é o que interessa. 
(21) FAUUSP, Edifício Vilanova Artigas, na Cidade Universitária
Para primeiro encontro de namoro é uma maravilha, o denominador é zero, $\Delta \mathrm{i}$ vai "pro" infinito; mas como varia no tempo, isto aqui vai crescendo, vai dando zebra, daí o cara se separa. Térmica é assim, iluminação é assim, acústica é assim, $\Delta \mathrm{i} / \mathrm{i}$, e "dt" porque é função no tempo, varia com o tempo.

E os caras falavam: você é louco, isso aqui é a primitiva de logaritmo! É logaritmo, e eu achava que o cara que não soubesse isso não podia fazer aula comigo. Com os caras da POLI, eu ensinava e eles me entendiam, eles sabiam, tinham estudado para o vestibular, logaritmo era obrigatório. Quando fui dar o curso, eu cheguei lá e vi que os caras não sabiam, eu falei: não dá "pra" dar aula. Vou mandar alguém para ensinar logaritmo para vocês.

RP: Continuando, depois do Chichierchio veio mais gente.

UDC: Depois veio outra geração, na década de 1970, quando só se pensava em revolução. Nessa época se pensava que a tecnologia não era importante, que o Departamento de Tecnologia, de Projeto, de História, nada era importante. Foi uma década esquisita, mas foi uma época em que o governo duplicou as vagas na Faculdade de Arquitetura, ainda na FAU Maranhão. Eram 40 vagas, e sobravam uns 70, 80 que não tinham passado, mas dobraram de 40 para 80 vagas, e entrou todo mundo; por isso, contrataram muitos professores e houve problemas de qualidade. Era muita gente de uma só vez. Aqui houve, realmente, um pepino. Pergunta "pra" todo mundo que participou desse processo.

Essa mudança foi muito importante, porque aumentou o número de vagas. Mas fizeram esta escola, este prédio ${ }^{21}$, no final dos anos 60, para 80 alunos. Depois, passaram para 150, e o Pompéia até hoje deve estar dizendo na tumba que ele acreditava nisso, que podiam caber os 150 alunos aqui; mas não tinha como, não podia caber o dobro; vai faltar tudo, vai faltar espaço, vai faltar banheiro, tudo. Ele escutou na Congregação que era tranqüilo fazer isso, que se dava um jeito. É muito importante entender esse processo. Passamos de 40 alunos por turma para 150 em um prazo muito curto. E isso representou um esforço de um monte de professores que entraram e depois tiveram dificuldades de acompanhar o que estava acontecendo, para fazer o necessário.

Foi uma expansão necessária, multiplicou-se por quatro o número de alunos e, no mínimo, por dois o número de professores, coisa que nunca aconteceu, mas a qualidade deixou a desejar em algum lugar, deixou alguns buracos.

Nesse processo nasceram disciplinas novas, na nossa área foram todas as de metodologia, de escultura para arquitetos e de ergonomia.

Quem participou desse processo foi o professor Teodoro Rosso. Ele ia fazer livre-docência, fez a tese em segurança contra incêndio, mas ele morreu e isso acabou. Ficou uma apostila dele que está aí na biblioteca. Ele estava montando um laboratório no IPT, ensinava aqui na FAU, e eu orientava informalmente a livre-docência dele porque eu tinha feito segurança contra incêndio na França; ele morreu no meio do caminho, infelizmente. Por sinal, ele tinha uma biblioteca espetacular, que a FAU comprou; ele tinha um outro apartamento só para essa biblioteca, era um cara importante.

RP: Como você vê a inserção dessas mudanças na grade curricular do ensino de tecnologia?

UDC: O Departamento de Tecnologia começou a ver essas lacunas por algumas pessoas - uma delas era o Teodoro Rosso - que precisavam completar essa coisa toda do desempenho, mas isso nunca foi feito como um todo. 
(22) ITQC, Ministério do Orçamento e Gestão, Caixa Econômica Federal. Processo de aceitação técnica de inovações tecnológicas: Manual do proponente. São Paulo, 1999.
Desempenho é metodologia. Quando você cria o desempenho, você tem a metodologia do desempenho e a metodologia da construção. Como constrói e qual o desempenho que eu quero? Eu preciso de todo mundo, dou uma primeira disciplina de desempenho, mostro todos os itens, e depois uma disciplina lá no quarto ano de fechamento. Nela tenho de montar um projeto executivo e fazer aqui o que chamo da junção de todo o processo construtivo, de todo o projeto, que nós não fazemos, com foco no desempenho, para responder a uma série de questões: a estrutura resiste a um incêndio? A ponte que projetei agüenta 0 impacto de um caminhão batendo no pilar? A ponte agüenta o vento ou entra em ressonância e cai? E assim, o projeto passa pelos 14 itens de desempenho: como vai ser a durabilidade, a manutenção da ponte? Vai 1 milhão de litros de tinta para pintar a ponte e 1 milhão de horas de trabalho para pintar? Compensa derrubar? A durabilidade é a manutenção a milhão.

A FAU não fechou essa questão do desempenho até hoje. Está na hora de fazer. É importante entender que, ainda hoje, falta essa cabeça central do desempenho, e que não é uma pessoa só. É uma coisa virtual. É toda uma estrutura. Aqui tem uma estrutura que pensa o desempenho e a construção, mais as outras três variáveis novas das quais ainda não falei.

Aqui, então, tenho um pensamento central no qual essas coisas se juntam. Tem o projeto executivo, que é o fim das disciplinas da construção, e pós-projeto executivo é que vem a avaliação do desempenho. É uma matriz de construção e desempenho. Não posso falar em estrutura sem falar em acústica, em desempenho térmico, em segurança contra incêndio, em durabilidade, em economia; estrutura tem de ser econômica.

E agora nascem as três novas variáveis do século 21: sustentabilidade, meio ambiente e responsabilidade social. Precisamos de três disciplinas novas no ensino da tecnologia. Essas três disciplinas talvez estejam no primeiro ano. Daí para frente segue o ensino da sustentabilidade, incluindo água, energia, tudo; na realidade, a sustentabilidade incluiria o meio ambiente, mas não é obrigado. $\mathrm{Na}$ verdade, posso manter alguma coisa sustentável sem ele.

E aí vem a responsabilidade social. Qual é a responsabilidade social? Quanto eu construo?; o salário mínimo da construção deveria ser de R\$1.000. Na construção não se deveria pagar menos de $\mathrm{R} \$ 1.000$ para nenhuma pessoa. Salário mínimo da construção deveria ser de $\mathrm{R} \$ 1.000$, em 20 dias trabalhados, $\mathrm{R} \$ 50$ por dia. Se o cara ganha $\mathrm{R} \$ 1.000$, ele se torna um consumidor, ele começa a viver. É o salário mínimo para o Brasil, já fiz as contas. É uma responsabilidade de quem projeta. Não teremos mais o tijolo sobre o tijolo, porque isso vai ficar muito caro. Só para milionário. Não vai ter tijolo, não, vai ter painel, mas é aqui dentro da faculdade que precisamos pensar nisso. É preciso acabar com essa brincadeira de hoje. Economia! Tem de ser viável economicamente.

E ainda hoje existe uma estrutura montada no tempo do Cintra, e são os três grupos de disciplinas do Departamento de Tecnologia: Construção (Ariosto Mila), Conforto (Cintra do Prado) e Metodologia (Philip Oliver Gunn).

Muito disso foi feito no tempo do BNH e no tempo da Caixa Econômica Federal, dessa coisa que não é muito velha, quando se começou a discutir as normas técnicas à avaliação de sistemas construtivos inovadores para habitações da Caixa ${ }^{22}$ 
(23) Laboratório Nacional de Engenharia Civil, em Lisboa, Portugal.

(24) As turmas do curso de graduação em Arquitetura e Urbanismo da FAUUSP são de 150 alunos/ano.
RP: Ualfrido, existe algum curso, alguma escola de arquitetura que funcione assim?

UDC: Aqui não! Lá fora, muitas. Muitas escolas de arquitetura em países desenvolvidos na Europa funcionam assim. Vocês precisam entender o seguinte: eles vão pela ISO, e depois vira regulamento da Comunidade Européia. E eles têm problemas em alinhar aqueles países todos, mas se você olhar o LNEC ${ }^{23}$, por exemplo, é isso aqui.

RP: Como deveria ser essa estrutura, de seu ponto de vista?

UDC: Então aqui, no campo do desempenho, estão faltando sete disciplinas: segurança contra incêndio, estabilidade da construção (nao é a estrutura, é para saber se é estável), estanqueidade, conforto tátil, adequação do espaço ao uso, que diz respeito à segurança ao uso (isso é arquitetura pura), economia tem, mas não é ligada ao desempenho e durabilidade (que não é manutenção, manutenção está dentro, mas é durabilidade). E isso é já insuficiente hoje, porque existem estas três coisas antes: sustentabilidade, meio ambiente e responsabilidade social. E tem de incluir: ISO 9000, controle de qualidade, porque sem qualidade não tem sustentabilidade; a ISO 14000, que é meio ambiente; e a ISO 26000, responsabilidade social. Essa é a nova concepção.

De repente, poderíamos ter, em vez de montar grandes disciplinas, poderíamos criar uma disciplina maluca, uma disciplina que oferecesse esse grande modelão para os alunos, de cara! Desempenho, construção, o que tem e o que não tem, como precisa ser, e já na primeira semana. Um susto! Depois, teríamos as várias disciplinas que ensinam cada coisa dessa aqui, separada: acústica, térmica, iluminação, ergonomia, uma disciplina para cada item de desempenho. Mas essa é uma disciplina pequenininha.

Aqui no meio tem uma disciplina: sustentabilidade, meio ambiente e responsabilidade social, dividindo 12 aulas em três módulos, de quatro em quatro.

E sou a favor de dividir as turmas, e não fazer como é hoje, mas em três turmas de 50, três disciplinas dadas ao mesmo tempo, com três professores para cada horário ${ }^{24}$. Podem ser oferecidas três disciplinas ao mesmo tempo para três turmas de 50. O cara faz tudo em um ano e meio, tudo mesmo, não tem conversa! Isso é para não inchar o sistema. Mas tem de começar por aí.

É necessário discutir um novo modelo para o ensino de tecnologia, mais moderno, uma estrutura mais contemporânea. O ensino de construção tem de retomar um curso de materiais "pra" valer! Eu sempre falo o seguinte: dá "pra" fazer um prédio de fibrocarbono? Lembre-se que fibrocarbono pesa muito pouco, tem uma enorme resistência ao fogo, é isolante termicamente! É um senhor material, e como é leve, mudaria até as fundações, de repente posso construir até em cima de um brejo. Está acabando a patente da DuPont. Vamos poder produzir fibra de carbono a preço de banana. Agora imagine um tijolo de $5 \mathrm{~g}$ que agüenta a compressão como os outros que temos por aí. Estou mostrando para vocês que precisamos dar um novo curso de materiais para os alunos! Precisamos incluir os novos vidros, novos materiais, novos sistemas e componentes. Mas daí você vê que muda o sistema de ensino de construção e de projeto. O mais importante é entender essa mudança de conceito, porque está acontecendo no mercado essa maluquice. 
(25) Referindo-se à carta solar para a latitude de São Paulo, $24^{\circ} \mathrm{S}$
RP: Nós gostaríamos que você falasse um pouco sobre certificação de edifícios. Você falou do desempenho, do ensino de tecnologia e dessas novas variáveis. A gente sabe que vive em um país de poucas normas, com uma noção muito superficial do desempenho, e que está em histeria pela certificação de edifícios. Não é isso? Você concorda?

UDC: Sim, e mais, muita coisa é malconstruída, muita coisa esquece o clima no qual estão localizados os edifícios, constrói-se igualzinho em São Paulo, Goiânia, Cuiabá (presta atenção, é quente "pra" encrenca aquilo lá, uma maravilha). E mais ainda! Tem gente fazendo casa de tijolinho em Campos do Jordão! E mais, na Serra da Canastra; é tudo igual.

Vamos passear pelo Brasil, fazer um tour, e a construção é sempre igual. E a orientação, então! Nem queiram saber. Eu morro de rir quando vou a um lugar diferente, e vejo as orientações mais aleatórias! Um verdadeiro absurdo... o cara não "tá" nem aí. Nunca me esqueço de alguém que me falou: "mas não tem outro modo, o terreno é assim!" Não dá os colarinhos! Vira um pouquinho! Se tenho janela aqui onde o sol não deve entrar, faço um terracinho torto, que já é o brise! Ah, meu bem!

Outra coisa que falta na construção é o estudo da condensação dentro da massa. Você já ouviu falar nisso? Passa um papel aí. É o seguinte: você tem uma parede, uma temperatura externa e uma temperatura interna. Se não for feito nada com a parede, isso aqui é poroso, a umidade entra, a temperatura externa baixa e a água condensa dentro da parede. 0 que acontece? Embolora a parede. Quer que te leve para ver isso em São Paulo? Você vai tirar fotografias aos milhares. É só olhar para a face sul, de onde vem o vento úmido e não bate sol nenhum por mais de seis meses, nem por uma hora. Ninguém enxerga isso!

Você já percebeu que aquela bola ${ }^{25}$ maluca tem uma curva assim, dizendo que uma fachada virada pra cá, a sul, não tem sol por mais de seis meses! Aquela bola maluca "tá" dizendo isso, é só olhar. Em São Paulo a fachada sul fica sem receber uma gotinha de sol, não recebe nem por uma hora, durante seis meses! No inverno é zero! Quando chegar o verão, ela pega essa coisa toda aqui e um pouquinho nos equinócios. No inverno todo o sol está do lado de lá, e é a maior parte do tempo.

O que você faz, então, para ele receber sol em todas as fachadas todo 0 ano? Vira o prédio! É tão fácil! E aí muda o projeto! Começam a aparecer uns brises bonitos, todos esquisitos. Vira o prédio a $45^{\circ}$, por exemplo, fica uma maravilha, todo mundo recebe sol, muda tudo. Você controla o que está acontecendo, aí o sol de verão já não esquenta tanto a face oeste por causa do ângulo, faz um tratamento diferenciado, você cria um corredor externo, para que esquente a parede de fora e não a do quarto, porque não tem jeito, cada lado é um lado. Já pensou que beleza um prédio com quatro fachadas diferentes? Em cada ângulo que você olha ele é de um jeito. Olha que maravilha! Essas construtoras sabem disso? Não sabem.

Você vai para fora, em um país frio, onde essa curva não é assim, o sol nunca passa a pino, você vê como a coisa é diferente! Os caras metem a tal da barreira de vapor, daí não tem problema. Entenderam o processo?

O que estão fazendo aqui na periferia? Depois que o problema aparece, pintam com impermeabilizante, um horror, fica aquela parede preta. Por causa da umidade, isso dá resfriado, pneumonia, tuberculose, ainda mais se você encostar 
a cama aqui. Isso diminui a resistência térmica da parede, a condutibilidade é a da parede úmida, o $\lambda^{26}$ muda.

Nós temos de mudar o pensamento! Isso aqui cai onde? No lado do desempenho? Na estanqueidade à umidade!

RP: Ualfrido, fale um pouco mais sobre certificação de edifícios.

UDC: Eu acabei de fazer uma lista na área de segurança contra incêndio das normas ISO e das normas da NFPA ${ }^{27}$; elas são mais ou menos dez vezes o que temos nas normas nacionais. Então, a normalização e a certificação no Brasil é meia-boca! Não temos laboratório para ensaiar tudo. Estamos atrasados e precisamos correr muito; e mais, precisamos de uma vontade política de novo, não só para montar os laboratórios, mas para criar um sistema parecido com esse de que estou falando, para ensaiar tudo desse ponto de vista e fechar o sistema. E tem mais, viu? É uma política tecnológica e industrial! Eu tenho de ser competitivo! Se quero vender produto brasileiro industrializado lá fora, preciso ter uma norma mais violenta do que a dos gringos! Como se faz isso? Com controle de qualidade muito mais violento.

Por exemplo, fazemos uma parede com $45 \mathrm{~dB}$ de isolação (lá fora é $40 \mathrm{~dB}$ ), que isola mais e teria de ter o mesmo preço! E nós podemos exportar. Mas tem de custar igual, no máximo $1 \%$ mais caro, posto lá, para ser competitivo no mundo. Quer ser competitivo, faz o que o japonês fez. O controle de qualidade japonês é assim - você não entra com seu produto no Japão e eles entram no mundo inteiro. E eles têm um valor de manutenção e de retorno dos produtos muito baixo; por isso, são muito competitivos.

Eles tornam mais rigorosas as normas internas, conseguem fazer pelo mesmo

(26) Condutibilidade térmica de materiais e componentes construtivos.

(27) National Fire Protection Association.

(28) ABNT - Associação Brasileira de Normas Técnicas. preço e não entra produto estrangeiro. Esse processo de controle de qualidade leva a menos rejeição, melhora da qualidade, diminuição de custo e competitividade.

Eu escutei o príncipe japonês dizer, quando a gente não conseguia vender soja para o Japão: "Compramos quanta soja vocês quiserem, desde que vocês entreguem dentro do nosso padrão interno." Era muito úmida a nossa soja, tinha de secar antes para poder mandar para o Japão. Não passava no controle de qualidade japonês. Isso é malandragem comercial tecnológica! Isso é política! É política de defender-se do produto do outro! No Japão vende-se produto chinês de monte, mas são os japoneses fazendo com o controle de qualidade, na China, o que eles querem; daí os outros não entram.

RP: Ualfrido, como você imagina que seria um bom sistema de certificação para o Brasil? Como seria uma formatação possível? Você acredita que sai a certificação nacional? Se sair, qual seria uma formatação possível, ou uma formatação ideal? Qual é a perspectiva?

UDC: Primeiro de tudo, precisamos de uma consciência empresarial. Vou te dizer por quê. Depois, uma consciência do consumidor e uma consciência do poder público da necessidade de um novo modelo! E não ficar fazendo normas aos borbotões, como estão fazendo, só para cobrir buraco das necessidades que temos mesmo! São esses três órgãos os participantes do processo na ABNT ${ }^{28}$. As empresas que produzem os produtos, os consumidores, que devem ser mais exigentes, e o poder público que vai participar desse processo para atingir o objetivo tecnológico vindo de fora, no processo global.

Nós somos competitivos em muitas áreas, meio sem querer, não me pergunte como aconteceu. Por exemplo, a área de sucos de laranja top de linha. Por quê? 
(29) Referindo-se aos novos edifícios de escritórios ao longo da Marginal do rio Pinheiros, em São Paulo.
Porque um empresário fez tudo sozinho! Quando começou a pressão do suco americano, da Califórnia, um cara fez tudo dentro da norma americana! Esse cara, o Cutrale, foi lá, sozinho! Cuidou de todos os papéis. O poder público, o governo brasileiro nunca ajudou em nada. Os produtores de lá estavam bravos porque o suco daqui estava chegando muito barato. Ele comprou as fabricas lá, fez um conglomerado, e pronto. Eles fazem uma mistura com o suco americano, e isso resolveu tudo. Você não ouve mais falar de suco. Por quê? Porque não mexe com o produtor, faz um blend Brasil/Estados Unidos, e está tudo resolvido. Alguém precisa fazer isso com o álcool! Ir pra lá, comprar as fábricas, as destilarias, misturar com o nosso e pronto. Precisa ir alguém daqui.

RP: $\mathrm{E}$ o edifício, Ualfrido?

UDC: O edifício, para ser certificado, precisa passar por essa mudança. É preciso implantar a rede nacional para a construção com a ISO 6241, que hoje é meia-boca por causa da Caixa Econômica, que fez isso só até cinco andares. Existe uma ISO 9000 de controle de qualidade, mas sem a ISO 6241 não tem jeito. Todas as outras normas ficam meia-boca! Como vou falar de qualidade (ISO 9000) e de meio ambiente (ISO 14000), se a ISO 6241 não foi implantada?

E aí precisa dizer qual certificação é essa, senão acontece o que a gente está vendo nos edifícios da Marginal29. Um edifício novo de escritórios - bati os olhos e vi que não passava na avaliação de segurança contra incêndio que mostrei lá no Corpo de Bombeiros. E já estão fazendo o prédio. De repente, lá no meio do salão tem um elevador privativo, vip, por onde pode passar o fogo e a fumaça. É um furo no projeto! Eu bati os olhos e vi. Como pode ter um buraco no prédio que pode passar fogo para todo lado?

RP: Então, essa certificação está vindo antes da avaliação básica de desempenho que nós ainda não temos.

UDC: Para a construção, tem de vir primeiro a avaliação do desempenho e depois a da qualidade em si! Um prédio classe AA deveria ter 45 dBA de isolação acústica nas paredes. Em qual avenida ele está? Qual é o ruído externo? Como vamos certificar algo que não tem a mínima preocupação com o desempenho? 0 processo está invertido!

RP: Há mais alguma coisa que você gostaria de abordar?

UDC: Tem. A ideologia nacional é parcial. O indivíduo diz que quer ser sustentável, que está preocupado com o meio ambiente, com o aquecimento global, o diabo, mas na realidade não faz nada para isso. Ideologia desligada da realidade. Isso se chama ter ética sem moral! Ética é a ciência que estuda o comportamento humano, ou seja, estuda a moral. Então a ética tem suas teorias, de o meio ambiente ser importante, de precisarmos parar com o aquecimento global, etc., e a moral é como se deve atuar para obter uma ética boa.

Qual é a moral judaico-católica? Não matarás! Não desejarás a mulher do próximo! Não isso, não aquilo, não, não, não. É toda uma teoria negativa, certo? Mas aqui não se fala em meio ambiente, em nada disso. A nossa moral está ligada aos sete pecados capitais ou aos dez mandamentos. Não tem conversa. E não se fala sobre meio ambiente. A natureza foi feita para o homem se apropriar como quiser. Essa é a nossa velha moral, ou ética.

A ética está lá, mas e a moral? Socialmente é complicado. Aqui está tudo meio confuso. A nova ética e a nova moral são muito mais complicadas. Existem muitos países preocupados em criar uma ética, estudando como fazer e 
aplicando, mudando a moral. Veja o exemplo dos saquinhos de supermercados: na França, eram 50 milhões de saquinhos/dia, sei lá, esse consumo caiu para 5 milhões, e o que eles querem é zerar nos próximos anos! Não vai mais ter saquinho. Por enquanto eles ainda estão pagando.

Tem um cara que foi a um supermercado e fez uma brincadeira de levar a cesta dele e pediu desconto, por não usar os saquinhos do supermercado. No preço de todo produto tem $0,01 \%$ a mais do custo da embalagem.

Agora todo mundo fala nisso, mas não faz, ou faz pela metade, só um pedacinho. Como vamos cuidar deste planeta? Todo mundo fala, mas ninguém anda a pé. Alguém vai até Guarulhos de ônibus, para buscar alguma coisa que pesa 20 Kg? Pega um táxi, pronto, aí já estragou.

RP: A cidade não está preparada?

UDC: As pessoas é que não estão preparadas. Se o cara quiser, ele faz. Ele fala: "eu vou fazer", e começa a fazer. Ninguém segura. Não me diz que não dá "pra" vir de sua casa até aqui de ônibus, porque dá. Não adianta falar não, porque é mentira. Tem ônibus de monte que pára aqui, dos dois lados da rua. Para ir para a minha casa tem dois; um dia pego do lado de lá, outro dia do lado de cá. Quando estou com vontade de andar, pego o ônibus na passarela, é morro abaixo, eu ando $700 \mathrm{~m}$. Quando não estou, vou até a Lapa, pego o Lapa/Clínicas e desço lá em cima. Moro em um dos piores lugares para pegar condução, só passa um ônibus perto de minha casa, é o Clínicas/Lapa. Primeiro tenho de pegar esse para ir a qualquer outro lugar, depois é que a viagem começa. Como é morro acima, se eu tiver com muita vontade de gastar energia, vou até a rua Cerro Corá, lá tem tudo para qualquer lugar.

Essa é a questão da ideologia que define essa nova realidade.

\section{Denise Duarte}

Professora doutora, orientadora do Programa de Pos-Graduação da FAUUSP na área de concentração Tecnologia da Arquitetura.

Joana Carla Soares Gonçalves

Professora doutora, orientadora do Programa de Pos-Graduação da FAUUSP na área de concentração Tecnologia da Arquitetura.

\section{Roberta Consentino Kronka Mülfarth}

Professora doutora do Departamento de Tecnologia da Arquitetura da FAUUSP.

Transcrição: Denise Duarte, Roberta Consentino Kronka Mülfarth e Rodrigo Cavalcante. Edição: Denise Duarte.

Colaboração: Joana Carla Soares Gonçalves e Khaled Ghoubar. 